\title{
Recurrent Hydatidiform Molar Pregnancy: A Case Report of 5 Consecutive Molar Pregnancies Complicated by HELLP and DIC, and Review of Literature
}

\author{
Fawaz Khaza'leh, Kareem Haloub*, Mazen Freij \\ Department of Obstetrics and Gynaecology, Faculty of Medicine, The University of Jordan, Amman, Jordan \\ Email: $\underline{\text { drhaloubk@gmail.com }}$
}

Received 2 July 2015; accepted 25 October 2015; published 29 October 2015

Copyright (C) 2015 by authors and Scientific Research Publishing Inc.

This work is licensed under the Creative Commons Attribution International License (CC BY). http://creativecommons.org/licenses/by/4.0/

(c) $\underset{\mathrm{EY}}{\mathrm{EP}}$ Open Access

\begin{abstract}
Hydatidiform mole is the most common form of gestational trophoblastic disease. Recurrent molar pregnancies are extremely rare. Herein, we reported the case of a patient with five consecutive molars; four of them were complete mole, and one was partial mole complicated by HELLP syndrome and DIC.
\end{abstract}

Keywords

HELLP, DIC, BHCG, GA, CVS, AST, ALT, IVF, PGD

\section{Introduction}

Hydatidiform mole is characterized by atypical hyperplastic trophoblasts and hydropic villi. It forms a heterogeneous group of disorders, with an incidence ranging from $1 / 500$ to $1 / 1500$ pregnancies. The incidence here in Jordan is unknown, whereas in Asia it reaches up to 1 in 80 pregnancies [1]-[3]. Although recurrent molar pregnancies are rare, its incidence is $1 \%-2 \%$ of all molar; it's clear that women who have a previous mole have a higher risk of recurrence than the general population [4].

Different hypertensive disorders can occur in pregnancy. Traditionally, PET is the new onset of hypertension (BP $\geq 140 \mathrm{mmHg}$ systolic, $\geq 90 \mathrm{mmHg}$ diastolic measured on two separate occasions) and proteinuria ( $\geq 0.3$ $\mathrm{g} /$ day) after 20 -week gestation in a previously normotensive patient. Case reports have reported very early PET (before 20-week gestation) in association with molar pregnancy, triploidy, Cushing syndrome and antiphospholipid syndrome. HELLP is considered as the severe form of PET when BP is $\geq 160 \mathrm{mmHg}$ systolic and $\geq 110$ ${ }^{*}$ Corresponding author. 
$\mathrm{mmHg}$ diastolic measured, and or headache, blurred vision, epigastric pain, and hematological manifestation.

\section{Case Report}

A 32-year-old Jordanian patient was first referred to our outpatient department at Jordan University Hospital in 2009 seeking pregnancy with a history of three molar pregnancies; all documented by histopathology. Two months later she had a spontaneous pregnancy, she was under regular antenatal visits, and nuchal translucency and nasal bone were seen by ultrasound at GA 12 weeks.

At 18 weeks gestation, she started to have a high BP; she was evaluated by the nephrology team and treated as a case of essential hypertension where she was started on methyldopa and Nifidipine. Three weeks later level 2 ultrasound done, revealed to have bulky placenta, otherwise normal level 2, amniocentesis done and the result revealed a tetraploidy pregnancy, three weeks later she was admitted to our hospital as a case of severe PET at GA 26 weeks, started on Metoprolol with methyldopa and Nifidipine, investigations revealed albumin: 1.7 gm/dl, HB: $6.82 \mathrm{gm} / \mathrm{dl}$, platelets: 95,000, liver function was AST: $18 \mathrm{U} / \mathrm{L}, \mathrm{ALT}: 25 \mathrm{U} / \mathrm{L}$ and coagulation profile fibrinogen: 8.0, FDP more than 20 (investigations are summarized in Table 1). So planned to terminate the pregnancy as the condition was deteriorating, and unable to control her blood pressure, caesarean section was done, outcome was alive male 1200 gram with no gross abnormality intubated directly, placenta sent for histopathology as it was grossly abnormal (Figure 1), she was given 4 units packed red blood cells, and 10 units fresh frozen plasma, and 5 units cryoprecipitate, 4 days later she was discharged home on Nifidipine and methyldopa with HB: $11.2 \mathrm{gm} / \mathrm{dl}$, and albumin: $3.1 \mathrm{gm} / \mathrm{dl}$.

Follow up with BHCG done for 9 months till it reached less than 1.2, one year later she got pregnant, BHCG revealed to be 200000IU, so planned to do suction evacuation and CVS, and the result revealed to be XXXX.

\section{Discussion}

The cause of molar pregnancy is unclear, however there are several factors. Molar pregnancy occurs at extreme

\begin{tabular}{ccc} 
Table 1. Details of investigations. \\
\hline Investigations & Pre Termination & Post Termination \\
\hline HB & $6.82 \mathrm{gm} / \mathrm{dl}$ & $11.2 \mathrm{gm} / \mathrm{dl}$ \\
Platelets & 95,000 & 160,000 \\
Albumin & $1.7 \mathrm{gm} / \mathrm{dl}$ & $3.1 \mathrm{gm} / \mathrm{dl}$ \\
Fibrinogen & 8 & 3 \\
FDP & More than 20 & Between 5 and 20 \\
ALT & $25 \mathrm{U} / \mathrm{L}$ & $16 \mathrm{U} / \mathrm{L}$ \\
AST & $18 \mathrm{U} / \mathrm{L}$ & $13 \mathrm{U} / \mathrm{L}$ \\
\hline
\end{tabular}

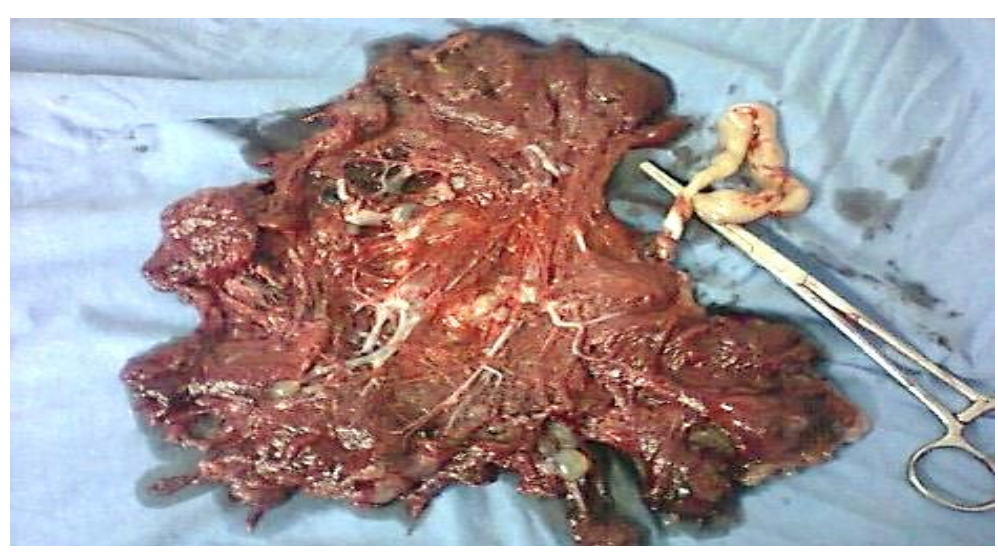

Figure 1. placentea looks grossly having VESICLES AND molar changes. 
ages. For women over 40 years of ages, there is a 10 fold increase, compared with only 1.3 fold increased risk in teenagers [2]. Other factors postulated to increase the risk of HM have included diet, gravity, and contraception [5] [6].

The incidence of recurrent molar pregnancy ranges from 5 to 40 fold increase in the current literature [3]. In to report from UK for women who had already had two molar pregnancies, the subsequent risk is 1 in 6.5 pregnancies [2], but this risk diminished if there is a normal pregnancy following HM.

Recurrent hydatidiform mole has significant pathological implication including risk of malignant sequels and poor reproductive performance. This risk of persistent trophoblastic disease is $22 \%$ after first molar and $50 \%$ after 2nd molar.

Familial predisposition has recently been evaluated. Familial recurrent HM is considered exceedingly rare with only 21 families reported in the medical literature. In these cases the HM is diploid, but biparental rather than androgenic in origin. These patients have an autosomal recessive condition, causing them to have recurrent molars, and they have little chance to have a successful pregnancy. Genetic studies revealed to have mutation in both alleles of the NLR7 or C6orf221/KHDC3L, which is located on chromosome 19q13.3 - q13.4 and these genes are predisposed to diploid parental mole, and diploid androgenic or triploid mole [7].

The case we have described is very early PET. There were no other risk factors for developing PET at such an early gestation as there. The mechanisms of PET remain incompletely understood. The condition appears to be caused by the abnormal placental invasion of the uterus leading to placental ischemia and widespread maternal endothelial dysfunction. Research has demonstrated that this endothelial dysfunction is likely contributed to by the inhibition of the endothelial growth factors vascular endothelial growth factor and placental growth factor one by the molecule soluble fims-like tyrosine kinase-1 as well as by the up-regulation of soluble endoglin (an anti-angiogenic factor) has no evidence of gestational trophoblastic disease [8].

Women with molar pregnancies had higher fibrinogen factor VIII, and fibrinogen degradation products, concentrations and lower prothrombin, factor $\mathrm{X}$, plasminogen, and plasminogen activator concentrations than controls with normal pregnancies. They also had reduced platelet counts and thromboelastographic values, which indicated hypocoagulability. These results suggest that intravascular coagulation occurs to intact hydatidiform molar pregnancies [9] [10].

Till now there is no further investigation other than genetic study, and till now there is no cure for those couples who have recurrent mole, even IVF and PGD it's not proved to have a role in management. And normal pregnancy is extremely rare in families with this condition.

\section{Conclusion}

Recurrent molar pregnancy is a genetically inherited disease related to childlessness, psychological trauma and increase incidence of malignancy. It's recommended that patients who present with recurrent molar pregnancy should be offered genetic testing aiding in counseling and prognosis for future pregnancy.

\section{References}

[1] Sebire, M.J. and Seckl, M.J. (2008) Gestational Trophoblastic Disease: Current Management Hydatidiform Mole. BMJ, 337, 452-458. http://dx.doi.org/10.1136/bmj.a1193

[2] Bagshawe, K.D., Rent, J. and Webb, J. (1986) Hydatiform Mole in England and Wales. The Lancet, 2, 673-677. http://dx.doi.org/10.1016/S0140-6736(86)90179-0

[3] Steigrad, S.J. (2003) Epidemiology of Gestational Trophoblastic Diseases. Best Practice \& Research: Clinical Obstetrics \& Gynaecology, 17, 837-847. http://dx.doi.org/10.1016/S1521-6934(03)00049-X

[4] AlMulhim, A.A. (2000) Hydatidiform Mole. JFCM, 7, 57-61.

[5] Sebri, N.J., Foskett, R.A., Fisher, R.A., Rees, H., Seckl, M. and Newlands, E. (2002) Risk of Partial and Complete Molal Pregnancy in Relationshipto Age. BJOG, 109, 99-102. http://dx.doi.org/10.1111/j.1471-0528.2002.t01-1-01037.x

[6] Palmer, R.J., Driscoll, S.G., Rosenberg, L., Berkowitz, R.S., Lurain, J.R., Soper, J., et al. (1999) Oral Contraception Use and Risk of Gestational Trophoblastic Tumours. Journal of the National Cancer Institute, 91, 635-640.

[7] Moglabely, Y.B., Kircheisen, R., Seoud, M., ElMogharbel, N., Van den Veyver, I. and Slim, R. (1999) Genetic Mapping of Maternal Locus Responsible for Familial Hydatidiform Moles. Human Molecular Genetics, 8, 667-671. http://dx.doi.org/10.1093/hmg/8.4.667 
[8] Madhudas, C., Khursheed, F. and Srichand, P. (2011) Analysis of Patients with Recurrent Molar Pregnancy. European Journal of biological Sciences.

[9] Thomas, W., Griffiths, M., Nelson-Piercy, C. and Sinnamon, K. (2012) Pre-Eclampsia before 20-Week Gestation: Diagnosis, Investigation and Management. Clinical Kidney Journal, 5, 597-599.

[10] Takok, F.H., Koh, S., Ratnam, S.S., et al. (1978) Coagulation and Fibrinolysis in Hydatidiform Molar Pregnancy. $B M J$.

\section{Abbreviations Used in the Text}

HELLP: Hemolysis Elevated Liver Enzymes, Low Platelets

DIC: Disseminated Intravascular Hemolysis

BHCG: Beta-Human Chorionic Gonadotropins

GA: Gestational Age

CVS: Chorionic Villus Sampling

AST: Aspartate Transaminase

ALT: Alanine Aminotransferase

IVF: In Vitro Fertilization

PGD: Pre-Genetic Diagnosis 